\title{
The Effects of Forkhead Box P2 Gene on Language Functional Articulation Disorder
}

\author{
Li-Yu Zhou
}

Hunan Engineering Polytechnic, Changsha, 410151, Hunan Province, China

\begin{abstract}
This study mainly concentrates on the discussion of the relationship between FOXP2 gene and language functional articulation disorder. The children of functional articulation disorder are selected, the normal healthy subjects in the corresponding period served as the controls, by contrasting with five polymorphic sites in FOXP2 gene to have a correlative study on human genes and language acquisition with the language barriers as main characteristics, in order to further prove the significance of FOXP2 gene in cultivating language and speech.
\end{abstract}

Keywords: FOXP2 Gene, Language, Articulation Disorder

\section{INTRODUCTION}

There only one thing in the world can be used for communication is creatures. Scientists found that in many human genes, FOXP2 gene enables people to speak; without this gene, people civilization and language won't have chance to go further. In the past several hundred thousand years, the change of FOXP2 is the root cause of promoting mankind to evolve towards different routes with other lives. Once this gene has been destroyed, it will lead to rare disorders of language, which may bring serious problems in language applications.

Functional articulation disorder, as called phonological disorder, is also known as functional pronunciation disorder, developmental aphthenxia. The researches on genetics mostly use speech sound disorder (Smith et al., 2005). Functional articulation disorder is commonly seen in children and Shriberg has reported that $15.6 \%$ of children in three and $3.8 \%$ of children in six have this kind of disease. In addition, Nathan reported that more than half of children with articulation disorder may have difficulties in language, reading and spelling (Nathan et al., 2004). Long-term follow-up studies have shown that compared with normal children, the children with functional articulation disorder significantly fell behind in high school, with generally low education and relatively poor occupations, most of which are semi-skilled or unskilled workers (Felsenfeld et al., 1994).

The FOXP2 gene (MIM605317) is the first speechrelated genes found in humans, speech disorder resulting from mutations of the gene also known as SPCH1 verbal injury (O'Brien et al., 2003), located in the 7q31 and belongs to the "FOX" gene family. The mutation of Exon $14 \mathrm{G} / \mathrm{A}$ in the FOXP2 gene leads to severe language and speech disorders of illness members in "KE" family, which mainly shows developmental verbal apraxia, comprehension and expression disorders for written and spoken language as well as orofacial fine motor disorders and so on. The average verbal IQ of patients is inferior to the average performance IQ (Marcus and Fisher, 2003). In addition, Lai et al. (2000) found out a boy irrelevant with "KE" family called "CS" boy, which has a similar language and speech disorders; his introne between exon $3 b$ and 4 in FOXP2 gene occurs breakage and translocation with No.5 chromosome ((5:7) (q22; q31.2)).

Thus, FOXP2 gene becomes an important candidate gene of language and speech disorders. Clinical manifestations of functional articulation disorder are similar with developmental verbal apraxia, 6-12\% of which is accompanied by language barriers and 38-62\% with expressive language disorders (Lewis et al., 2006). Based on the above, this research chooses five SNPS in 
FOXP2 gene as rs923875, rs2396722, rs1852469, rs17137124 and rs51456031 by comparing allele and genotype frequency in 150 children of functional articulation disorders and 140 healthy subjects and haplotype analysis is performed according to linkage imbalanced results, aiming at discussing the correlation of FOXP2 gene and functional articulation disorders.

\section{EXPERIMENTAL MATERIALS}

\subsection{Subjects}

About 150 individuals of functional articulation disorders are Han Chinese without any relationships by blood, while 109 males and 41 females with the average of $6.45 \pm 2$ and mild cases are 42 and moderately severe cases are 108 . Confirmed by the hospital, the diagnostic criteria of functional articulation disorder developed by Audition Linguistics Society of Japan (Dingxiang and Shengli, 1998) is that: Functional articulation disorder refers to the abnormality of stgotless articulators and function and language has developed to the age of four, but still appears articulation errors with a fixed state.

According to Diagnostic and Statistical Manual of American Mental Disorder DSM-IV, the generalized standardized pronunciation disorder diagnosis is as follows:

- The pronunciation which is equivalent of the age and native language isn't applied

- The problems of speech affect studies, work or social activities

- If there are metal retardation, speech movement, sensory disturbances or environmental deprivation, the speech difficulty should exceed speech problems associated with the disease itself

However, functional articulation disorder refers to pronunciation disorders in a narrow sense, namely developmental phonological disorder, which means a disease of unknown etiology. There is no specific age limits in DSM-IV, considering that language development has reached to its age but its articulation still fall behind, which means functional articulation disorder can be diagnosed, thus this study uses the diagnostic criteria developed by Audition Linguistics Society of Japan.

The grading system of functional articulation disorder is: According to others' understanding on children language to decide the severity of articulation disorder, with only one or two words said for unsure, but basically has no impact on others' understandings, as is mildly; it's moderate that others find it hard to understand its language content, but for others who are familiar with can understand fundamentally; for severe conditions, it means there are a lot of words hard to explain, even with the most familiar people such as mother or trusty people still often don't know the content to be expressed (140 healthy controls).

\subsection{Experimental Methods}

- Ask for details of the history

- Asking for details of the history including starting with the words, phases and the age of sentence, the understanding of family members and others on children language and so on, it can determine the severity of dysarthria.

- Mental test

- Intelligence evaluation

- Intelligence evaluation can use ChinaWechesler Young Children Scale of Intelligence (C-WYCSI) or China-Wechsler Intelligence Scale for Children (C-WISC) revised by Yao-Xian Gong of Hunan Medical University

- Language development evaluating

- It uses Peabody Picture Vocabulary Test (PPVT) to evaluating the level of language development and children less than four years old are not included in the study

- Articulation evaluation

- It uses articulation evaluation scale of China Rehabilitation Research Center

- Genomic DNA extraction

- It uses $2 \mathrm{~mL}$ of venous blood, $1.5 \%$ of EDTA anticoagulant and phenol chloroform isoamyl alcohol to extract genomic DNA

- Primer design and synthesis

- It considers the selected five polymorphic sites as genetic marker, involving primer sequence, amplified fragment, restriction enzyme and enzyme-digested product in various SNPS sites

- $\quad$ PCR reactive conditions

- Concrete PCR reactive conditions various SNPS sites

- Genotype

- It employs the method of Restricted Fragment Length Polymorphisms (RFLP) for allelic genotyping in various SNPS sites, restriction enzyme and enzyme-digested method; placing the enzyme reaction products at the sample hole with 2 or $2.5 \%$ agarose gel (add Ethidium 
Bromide in the proportion of $1 / 10000$ ) and setting the voltage $100 \mathrm{~V}$ for electrophoresis in 1 TBE solution about 40 to $60 \mathrm{~m}$. After then, it images in the gel automatic imaging system and records the various genotypes of SNPS

- Direct sequencing analysis

- By comparison of sequencing, enzyme analysis and gene order NC000007.12 of human FOXP2 gene in Gene Bank; it can determine the variation of sequence

- Statistical analysis

- It uses Shesis online software to analyze allelic genes, genotypes, haplotyppe frequencies and their group differences in various sites and calculates $\chi^{2}$, OR value and $95 \%$ of confidence interval. Statistical significance tests are all twosided, with $\mathrm{p}<0.05$ as a statistical difference

\section{EXPERIMENTAL RESULTS}

\subsection{Allele and Genotype Distributions of Polymorphic Sites in FOXP2 Gene of Normal People and People with Functional Articulation Disorder}

There are five single nucleotide polymorphic sites in FOXP2 gene as rs5923875, rs52396722, rs51852469, rs17137124 and rs51456031, where the distribution of allele and genotype frequencies are all in line with the law of Hardy-Weinberg equilibrium in normal controls and the groups of functional articulation disorder, as shown in Table 1. The samples that are failed by PCR or enzyme digestion for many times in cases are: Four in site rs51852469, two in site rs51713712.

\subsection{Correlation Analysis of Various Sites and Functional Articulation Disorder}

\subsubsection{Linkage Disequilibrium Analysis}

Linkage disequilibrium analysis results show that three polymorphic sites in cases rs2396722, rs923875 and rs1852469 have a strong linkage disequilibrium (D $>0.5)$, but weak in other sits (Table 3).

\subsection{Haplotype Analysis on Polymorphic Sites on FOXP2 Gene of Cases and Controls}

Owing to a single genetic marker has a small statistical effect on correlation analysis, the haplotype constituted by several genetic markers with high linkage disequilibrium can provide more genetic information to increase the effectiveness of statistics. Therefore, based on linkage disequilibrium analysis results, it can divide into groups with the $\mathrm{D}$ value among polymorphic sites, to form a group of site with high linkage disequilibrium (D’>0.5) for haplotype analysis.

During five single nucleotide polymorphic sites, between rs5923875 and rs52396722, rs2396722 and rs51852469, there has a strong linkage disequilibrium, D'>0.5 (Table 1 and 2). Thus, the distribution of common haplotype frequencies formed by three SNPS sites (rs923875A/C, rs2396722C/T and $\mathrm{rS} 1852469 \mathrm{~A} / \mathrm{T}$ ) is presented in Table 3. Common haplotype refers to the haplotype that cases or controls are greater than 3\%. Results show that frequency in haloptype rs923875A/+rs2396722T/ + rs $1852469 \mathrm{~T}$ in cases is significantly higher than the controls $(\mathrm{p}=$ $0.0103, \mathrm{OR}=1.752,95 \% \mathrm{Cl}: 1.138 \sim 2.695$, Global $\mathrm{P}=$ 5.68e-006), as shown in Table 4.

Table 1. Allele and genotype frequency in polymorphic sites of FOXP2 gene between cases and controls

\begin{tabular}{|c|c|c|c|c|c|}
\hline \multirow{2}{*}{$\begin{array}{l}\text { Polymorphic site } \\
\text { SNP (cases) } \\
\text { rs923875 }\end{array}$} & \multicolumn{3}{|c|}{-------------------Genotype frequency (\%)------------------ } & \multicolumn{2}{|c|}{--------Allele frequency $(\%)------$} \\
\hline & $\mathrm{CC}$ & $\mathrm{AC}$ & $\mathrm{AA}$ & A & $\mathrm{C}$ \\
\hline Patients (150) & $56(0.37)$ & $70(0.47)$ & $24(0.16)$ & $118(0.393)$ & $182(0.607)$ \\
\hline Controls (140) & $53(0.38)$ & $71(0.51)$ & $16(0.11)$ & $103(0.368)$ & $177(0.632)$ \\
\hline rs2396722 & $\mathrm{CC}$ & CT & TT & $\mathrm{C}$ & $\mathrm{T}$ \\
\hline Patients (150) & $40(0.27)$ & $76(0.51)$ & $34(0.22)$ & $156(0.520)$ & $144(0.480$ \\
\hline Controls (138) & $40(0.29)$ & $72(0.52)$ & $26(0.19)$ & $152(0.551)$ & $124(0.449)$ \\
\hline rs 1852469 & AA & AT & $\mathrm{TT}$ & A & $\mathrm{T}$ \\
\hline Patients (146) & $14(0.130)$ & $44(0.407)$ & $50(0.463)$ & $72(0.333)$ & $144(0.667)$ \\
\hline Controls (137) & $24(0.175)$ & $79(0.577)$ & $34(0.248)$ & $127(0.464)$ & $147(0.536)$ \\
\hline rs17137124 & $\mathrm{CC}$ & $\mathrm{CT}$ & TT & $\mathrm{C}$ & $\mathrm{T}$ \\
\hline Patients (148) & $20(0.14)$ & $82(0.56$ & $24(0.16)$ & $166(0.561)$ & $130(0.439)$ \\
\hline Controls (140) & $56(0.40)$ & $62(0.44)$ & $22(0.16)$ & $174(0.621)$ & $106(0.379)$ \\
\hline rs1456031 & $\mathrm{CC}$ & $\mathrm{CT}$ & TT & $\mathrm{C}$ & $\mathrm{T}$ \\
\hline Patients (150) & $42(0.28)$ & $78(0.52)$ & $30(0.2)$ & $162(0.540)$ & $138(0.460)$ \\
\hline Controls (138) & $39(0.28)$ & $73(053)$ & $26(0.19)$ & $151(0.547)$ & $125(0.453)$ \\
\hline
\end{tabular}


Table 2. Correlation analysis of various sites and functional articulation disorder based on Table 1

\begin{tabular}{lllllll}
\hline 位点 & Allele $\chi^{2}$ & Allele $\rho$ & Genotype $\chi^{2}$ & Genotype $\rho$ & Allele comparison & Comparison of two genotypes \\
\hline rs923875 & 0.399 & 0.5280 & 0.346 & 0.510 & No significant difference & No significant difference \\
rs2396722 & 0.545 & 0.4600 & 1.676 & 0.713 & No significant difference & No significant difference \\
rs1852469 & 9.129 & 0.0126 & 13.772 & 0.001 & Have significant difference & Have significant difference \\
rs17137124 & 2.186 & 0.1390 & 4.646 & 0.098 & No significant difference & No significant difference \\
rs1456031 & 0.029 & 0.8640 & 0.062 & 0.969 & No significant difference & No significant difference \\
\hline
\end{tabular}

(While $\mathrm{P}$ value in rs1852469 is Bangfuleini corrected value)

Table 3. Linkage disequilibrium analysis results of five polymorphic sites in FOXP2 site

\begin{tabular}{|c|c|c|c|c|c|}
\hline SNPs & 923875 & 2396722 & 1852469 & 17137124 & 1456031 \\
\hline rs923875 & - & 0.579 & 0.232 & 0.071 & 0.295 \\
\hline rs2396722 & 0.336 & - & 0.506 & 0.009 & 0.188 \\
\hline rs 1852469 & 0.211 & 0.182 & - & 0.14 & 0.104 \\
\hline rs17137124 & 0.237 & 0.379 & 0.226 & - & 0.212 \\
\hline rs 1456031 & 0.096 & 0.079 & 0.113 & 0.139 & - \\
\hline
\end{tabular}

Table 4. Haplotype frequencies distribution of three polymorphic sites in FOXP2 gene between cases and controls

\begin{tabular}{lllllllll}
\hline Number & Haplotype & Patients & Controls & $\chi^{2}$ & P-value & OR & $95 \%$ CI & Global P \\
\hline 1 & ACA & 0.045 & 0.050 & 0.102 & 0.7493 & 0.881 & $0.405-1.918$ & $5.68 \mathrm{E}-06$ \\
2 & ACT & 0.042 & 0.078 & 3.319 & 0.0685 & 0.514 & $0.249-1.063$ & \\
3 & ATA & 0.073 & 0.086 & 0.309 & 0.5786 & 0.841 & $0.456-1.551$ & $1.138-2.695$ \\
4 & ATT & 0.234 & 0.149 & 6.590 & 0.0103 & 1.752 & $0.609-1.337$ & \\
5 & CCA & 0.221 & 0.239 & 0.262 & 0.6086 & 0.902 & $0.847-1.956$ \\
6 & CCT & 0.217 & 0.177 & 1.397 & 0.2374 & 1.287 & $0.825-2.094$ \\
7 & CTT & 0.168 & 0.134 & 1.329 & 0.2490 & 1.314 & \\
\hline
\end{tabular}

Table 5. The comparison of allele and genotype frequencies in polymorphic sites in FOXP2 gene between mild cases and controls Polymorphic sites

\begin{tabular}{|c|c|c|c|c|c|c|c|}
\hline SNP (cases) & -----------G & ge frequenc & --------- & $\chi^{2}$ & ------Allele & 'cy (\%)------ & $\chi^{2}$ \\
\hline rs923875 & $\mathrm{CC}$ & $\mathrm{AC}$ & AA & & $\mathrm{A}$ & $\mathrm{C}$ & \\
\hline Patients (42) & $16(0.381)$ & $20(0.476)$ & $6(0.143)$ & 0.281 & $32(0.381)$ & $52(0.619)$ & 0.047 \\
\hline Controls (140) & $53(0.379)$ & $71(0.507)$ & $16(0.114)$ & & $103(0.368)$ & $177(0.632)$ & \\
\hline rs 2396722 & $\mathrm{CC}$ & $\mathrm{CT}$ & $\mathrm{TT}$ & & $\mathrm{C}$ & $\mathrm{T}$ & \\
\hline Patients (42) & $15(0.357)$ & $23(0.548)$ & $4(0.095)$ & 2.195 & $53(0.631)$ & $31(0.369)$ & 1.691 \\
\hline Controls (138) & $40(0.290)$ & $72(0.522)$ & $26(0.188)$ & & $152(0.551)$ & $124(0.449)$ & \\
\hline rs 1852469 & $\mathrm{AA}$ & $\mathrm{AT}$ & $\mathrm{TT}$ & & A & $\mathrm{T}$ & \\
\hline Patients (38) & $6(0.158)$ & $15(0.395)$ & $17(0.447)$ & 5.935 & $27(0.355)$ & $49(0.645)$ & 2.829 \\
\hline Controls (137) & $24(0.175)$ & $79(0.577)$ & $34(0.248)$ & & $127(0.464)$ & $147(0.536)$ & \\
\hline rs17137124 & $\mathrm{CC}$ & $\mathrm{CT}$ & $\mathrm{TT}$ & & $\mathrm{C}$ & $\mathrm{T}$ & \\
\hline Patients (42) & $10(0.238)$ & $26(0.619)$ & $6(0.143)$ & 4.452 & $46(0.548)$ & $38(0.542)$ & 1.472 \\
\hline Controls (140) & $56(0.400)$ & $62(0.443)$ & $22(0.157)$ & & $174(0.621)$ & $106(0.379)$ & \\
\hline rs1456031 & $\mathrm{CC}$ & $\mathrm{CT}$ & TT & & $\mathrm{C}$ & $\mathrm{T}$ & \\
\hline Patients (42) & $16(0.381)$ & $21(0.500)$ & $5(0.119)$ & 1.97 & $53(0.631)$ & $31(0.369)$ & 1.844 \\
\hline Controls (138) & $39(0.283)$ & $73(0529)$ & $26(0.188)$ & & $151(0.547)$ & $125(0.453)$ & \\
\hline
\end{tabular}

\subsection{Correlation Analysis of Polymorphic sites in FOXP2 Gene between Normal People and Patients with Various Degrees}

Comparing the patients of functional articulation disorder after grouping based on the severity of the disease with the controls, genotype frequency and allele frequency of five polymorphic sites in FOXP2 gene between 42 mild cases and controls have no significant difference, shown in Table 5.
Comparing 108 moderately severe cases with the controls, the allele frequency in site rs51852469 has a significant difference $\left(\mathrm{x}^{2}=12.379, \mathrm{P}=0.00210\right.$ and $\mathrm{P}=$ 0.0105 after the bangfuleini correction) and allele frequencies in site rs 1852469 also have a great difference $\left(\mathrm{x}^{2}=8.486, \mathrm{p}=0.0036, \mathrm{P}=0.018\right.$ after the bangfuleini correction). The rest four sites of allele frequency and genotype frequency all have no significant difference as shown in Table 6. 
Table 6. The comparison of allele and genotype frequencies in polymorphic sites in FOXP2 gene between moderately severe cases and controls

\begin{tabular}{|c|c|c|c|c|c|c|c|}
\hline \multirow{2}{*}{$\begin{array}{l}\text { Polymorphic sites } \\
\text { SNP (cases) } \\
\text { rs923875 }\end{array}$} & \multicolumn{3}{|c|}{----------Genotype frequency (\%)----------- } & \multirow[t]{2}{*}{$\chi^{2}$} & \multicolumn{2}{|c|}{------Allele frequency (\%)------ } & \multirow[t]{2}{*}{$\chi^{2}$} \\
\hline & $\mathrm{CC}$ & $\mathrm{AC}$ & AA & & $\mathrm{A}$ & $\mathrm{C}$ & \\
\hline Patients (108) & $40(0.370)$ & $50(0.4630$ & $18(0.167)$ & 1.475 & $86(0.398)$ & $130(0.602)$ & 0.474 \\
\hline Controls (140) & $53(0.379)$ & $71(0.507)$ & $16(0.114)$ & & $103(0.368)$ & $177(0.632)$ & \\
\hline rs2396722 & $\mathrm{CC}$ & $\mathrm{CT}$ & TT & & $\mathrm{C}$ & $\mathrm{T}$ & \\
\hline Patients (108) & $25(0.231)$ & $53(0.491)$ & $30(0278)$ & 2.195 & $103(0.477)$ & $113(0.523)$ & 2.649 \\
\hline Controls (138) & $40(0.290)$ & $72(0.522)$ & $26(0.188)$ & & $152(0.551)$ & $124(0.449)$ & \\
\hline rs1852469 & $\mathrm{AA}$ & $\mathrm{AT}$ & TT & & A & $\mathrm{T}$ & \\
\hline Patients (108) & $14(0.130)$ & $44(0.407)$ & $50(0.463)$ & 5.935 & $72(0.333)$ & $144(0.667)$ & 8.486 \\
\hline Controls (137) & $24(0.175)$ & $79(0.577)$ & $34(0.248)$ & & $127(0.464)$ & $147(0.536)$ & \\
\hline rs17137124 & $\mathrm{CC}$ & $\mathrm{CT}$ & $\mathrm{TT}$ & & $\mathrm{C}$ & $\mathrm{T}$ & \\
\hline Patients (106) & $32(0.302)$ & $56(0.528)$ & $18(0.17)$ & 4.452 & $120(0.566)$ & $92(0.434)$ & 1.539 \\
\hline Controls (140) & $56(0.400)$ & $62(0.443)$ & $22(0.157)$ & & $174(0.621)$ & $106(0.379)$ & \\
\hline rs1456031 & $\mathrm{CC}$ & $\mathrm{CT}$ & TT & & $\mathrm{C}$ & $\mathrm{T}$ & \\
\hline Patients (108) & $26(0.241)$ & $57(0.528)$ & $25(0.231)$ & 1.97 & $109(0.505)$ & $107(0.495)$ & 0.877 \\
\hline Controls (138) & $39(0.283)$ & $73(0529)$ & $26(0.188)$ & & $151(0.547)$ & $125(0.453)$ & \\
\hline
\end{tabular}

Note: $* \mathrm{P}=0.0021$ and $* \mathrm{P}=0.0036$ will be $* \mathrm{P}=0.0105$ and $* \mathrm{P}=0.018$ after the Bonferroni correction

\section{FOXP2 GENE STRUCTURES AND FUNCTIONS}

FOX family members are key transcription factors in the process of embryogenesis. Forkhead box $\mathrm{p} 2$ (FOXP2) gene is one of the FOX families, which has an Open Reading Frame (ORF) with $2.1 \mathrm{~kb}$ long. It contains 19 exons, therein $3 \mathrm{a}$ and $3 \mathrm{~b}$ can be selected to cut. No.5 and No. 6 in exons encode polyglutamine tract and No.12 to 14 encodes are representative DNA-binding domain consisted of 84 amino acids. Bruee and Margolis (2002) also discovered six untranslated exons and the length of FOXP2 gene had reached to $603 \mathrm{~kb}$.

FOXP2 protein as a transcription factor has a regulating effect on other cellular heredity and the expression of other genes' lung tissue, cardiovascular, intestinal and nerves in development. Several targeted genes in FOXP2 gene have been discovered in human brain including axon and the frontal cortex so far (Sonja et al., 2007). The study in vitro by Spiteri et al. (2007) has confirmed the regulation of FOXP2 gene; in addition, many of these targeted genes in FOXP2 gene play a crucial role in CNS development such as the growing of axons.

\section{FOXP2 GENE AND FUNCTIONAL ARTICULATION DISORDERS}

There are few studies about FOXP2 gene and functional articulation disorders in China. Functional articulation disorder is a complex disease and its pathogenesis is a process of a multi-factor and polygene involved. For some complex diseases, we usually use a correlation method. The most suitable genetic marker for the study is Single Nucleotide Polymorphism (SNP). SNP in the coding region and regulation sequences has a more significance in functional or medical treatment; in order to clarify the disease mechanism, we should conduct a comparative analysis on SNP cases, because only in this way can it possible to get a clear relationship between SNP and abnormal phenotypes for the purpose. Besides, more and more studies have shown the polymorphism in genome is conductive to explain the phenotypic differences of individuals, the susceptibility of various groups and individuals for disease, particularly the complex polygenic disease.

The study of haplotype has discovered that the frequency of haplotype rs $923875 \mathrm{~A} /+\mathrm{rs} 2396722 \mathrm{~T} / \mathrm{rS} 1852469 \mathrm{~T}$ in cases is higher than the controls $\left(\chi^{2}=6.590 \%, \mathrm{p}=0.0103, \mathrm{OR}=\right.$ 1.752, 95\% $\mathrm{Cl}: 1.138 \sim 2.695$, Global $\mathrm{P}=5.68 \mathrm{e}-006)$, which indicates that this haplotype may be correlated with the functional articulation disorder. rs5923875, rs52396722 and rs1852469 are located in five untranslated regions and upstream of ATG transcription initiation codon, which are likely to take participant in regulating FOXP2 gene transcription.

By respectively comparing normal people with the people of functional articulation disorder after grouping based on the severity degrees, the results show that five polymorphic sites in FOXP2 gene are uncorrelated with the mild cases; for moderately severe cases, allelic 
frequency in site rs51852469 is higher than the controls $\left(\chi^{2}=8.486, p=0.0036, p=0.01\right.$ after the bangfuleini correction); there is still a significant difference in comparing two genotypes of $\left(\chi^{2}=12.379, p=0.0021, p\right.$ $=0.0105$ after the bangfuleini correction), which illustrates that the site rs 1852469 in FOXP2 gene has a correlation with moderately severe functional articulation disorder.

FOXP2 gene has been high-expressed in fetal and adult brain, especially in the cerebral cortex, cerebellum Po kenye neurons, thalamus, basal ganglion, inferior olive and cerebellum. Basal ganglion is a functional integrity of a series of neural nuclei in the brain. Single nucleotide polymorphic sites located in gene control center may affect the expression of FOXP2 gene on basal ganglion, resulting in a fine oral dyskinesia. The clinical results also show that apart from the cerebral palsy and myodystrophy that cause dysarthria, there still some children have an inflexible oral movement and poor proprioception of the tongue, but lacks a strong objective basis. The research of real-time brain functions in children with functional articulation disorder by Functional Magnetic Resonance Imaging (FMRI) contributes to understand the basal ganglia activities in brain whether it's unusual or not.

\section{CONCLUSION}

We can draw a conclusion from the experimental data that FOXP2 gene damages are associated with the functional articulation disorder susceptibility and allele gene rs1852469T in FOXP2 gene may be an important factor to determine this functional articulation disorder susceptibility of individuals. In addition, it can be seen from this study that individuals with the haloptype rs923875A/+rs2396722T/+rs1852469T in FOXP2 gene have a $\mathrm{n}$ increasing relative risk of functional articulation disorder, but in individuals with the haloptype s923875C/+rs2396722C/+rS1852469A are reduced. Thus, it can be concluded that FOXP2 gene may be a gene with a genetic predisposition of functional articulation disorder, which provides a theoretical basis for the future negative language research and the treatment of language diseases.

\section{REFERENCES}

Bruee, H.A. and R.L. Margolis, 2002. FOXP2: Novel exons, splice variants and CAG repeat length stability. Hum. Genet., 111: 136-144. DOI: 10.1007/s00439-002-0768-5
Dingxiang, F. and L. Shengli, 1998. Speech Therapy of functional articulation disorders speech therapy of functional articulation Disorders $\$ \$ \$ / F e n g$ Dingxiang; Li Shengli //(Chinese). Chinese J. Rehab. Theory Pract., 4: 64-66.

Felsenfeld, S., P.A. Broen and M. McGue, 1994. A 28Year follow-up of adults with a history of moderate phonological disorder. J Speech Language Hear. Res., 37: 1341-1353. DOI: 10.1044/jshr.3706.1341

Lai, C.S.L., S.E. Fisher, J.A. Hurst, E.R. Levy and S. Hodgson et al., 2000. The SPCH1 region on human 7q31: Genomic characterization of the critical interval and localization of translocations associated with speech and language disorder. Am. J. Hum. Genet., 67: 357-368. DOI: 10.1086/303011

Lewis, B.A., L.D. Shriberg, L.A. Freebairn, A.J. Hansen and C.M. Stein et al., 2006. The genetic bases of speech sound disorders: Evidence from spoken and written language. J. Speech Lang. Hear. Res., 49: 1294-1312. DOI: 10.1044/1092-4388(2006/093)

Marcus, G.F. and S.E. Fisher, 2003. FOXP2 in focus: What can genes tell us about speech and language? Trends in Cognitive Sci., 6: 257-262. DOI: 10.1016/S1364-6613(03)00104-9

Nathan, L., J. Stackhouse, N. Goulandris and M.J. Snowling, 2004. Educational consequences of developmental speech disorder: Key Stage 1 National Curriculum assessment results in English and mathematics. Br. J. Educ. Psychol., 74: 173186. DOI: $10.1348 / 000709904773839824$

O'Brien, E.K., X. Zhang, C. Nishimura, J.B. Tomblin and J.C. Murray, 2003. Association of Specific Language Impairment (SLI) to the Region of 7q31. Am. J. Hum. Genet., 72: 1536-1543. DOI: $10.1086 / 375403$

Smith, S.D., B.F. Pennington, R. Boada and L.D. Shriberg, 2005. Linkage of speech sound disorder to reading disability loci. J. Child Psychol. Psychiatry, 46: 10571066. DOI: $10.1111 / j .1469-7610.2005 .01534 . x$

Spiteri, E., G. Konopka, G. Coppola, J. Bomar and M. Oldham et al., 2007. Identification of the transcriptional targets of FOXP2, a gene linked to speech and language, in developing human brain. Am. J. Hum. Genet., 81: 1144-1157. DOI: 10.1086/522237

Sonja C.Vernes, S.C., E. Spiteri, J. Nicod, M. Groszer and J.M. Taylor et al., 2007. High-throughput analysis of promoter occupancy reveals direct neural targets of FOXP2, a gene mutated in speech and language disorders. Am. J. Hum. Genet., 81: 12321250. DOI: $10.1086 / 522238$ 